DOI: $10.20472 / T E .2016 .4 .3 .002$

\title{
INCONSISTENCIES IN TEXTBOOK PRESENTATION OF SUBSTITUTION AND INCOME EFFECTS
}

\author{
JULIEN PICAULT
}

\begin{abstract}
:
Labour economics textbooks present inconsistent methods for determining substitution and income effects. Hicks (1939) and Samuelson (1953) developed two different methods separating substitution and income effects. While both methods result in the same conclusion regarding the direction of the effects, they differ on magnitude of the effects. Furthermore, economics instructors are typically unaware of the inconsistency in labour economics textbooks, causing them to consider students' answers as incorrect when they may not be. This paper advocates for the selection of a standard approach in labour economics instruction, and acknowledges that these different methods are currently a source of confusion for students.
\end{abstract}

\section{Keywords:}

Substitution effect, Income effect, Textbook, Cost-Difference, Compensating Variation

JEL Classification: A20

\section{Authors:}

JULIEN PICAULT, UBC Okanagan, Canada, Email: julien.picault@ubc.ca

\section{Citation:}

JULIEN PICAULT (2016). Inconsistencies in Textbook Presentation of Substitution and Income Effects. International Journal of Teaching and Education, Vol. IV(3), pp. 7-15., 10.20472/TE.2016.4.3.002 


\section{Introduction}

Microeconomics and labour economics courses require instructors to provide students with a method for separating income from substitution effects. In microeconomics textbooks, the presentation of this method is standardized, while in labour economics textbooks it is not. This discrepancy is a significant source of confusion for both instructors and students. This paper aims at highlighting the different methods for separating income from substitution effects in labour economics textbooks and advocates for similar standardization than in microeconomics textbooks.

Slutsky (1915) initially presented a method separating income and substitution effects ${ }^{1}$; however, this method is no longer commonly presented in textbooks. Hicks (1939) then introduced a more tractable method to separate income and substitution effects. ${ }^{2}$ Later, Samuelson (1953) refined the separation method introduced by Hicks. Hicks (1956) clearly describes the difference between the method he developed in 1939 and the method presented in Samuelson (1953). Microeconomics textbooks are consistent in presenting Samuelson's method, which creates standardization; while labour economics textbooks continue to use both methods interchangeably. It is the use of both methods which leads to a lack of consistency for students and instructors. In order to differentiate the two methods, Hicks (1956) labeled his 1939's method: the method of the Compensating Variation and Samuelson (1953)'s method: the method of the Cost-Difference. The Compensating Variation method is not presented in standard microeconomics textbooks. ${ }^{3}$

The economic theory of labour supply is a part of the economic theory describing consumer behaviour, which is why substitution and income effects are presented in labour economics textbooks. Although most labour economics textbooks propose an extensive study of substitution and income effects, they do not consistently present the same method.

To illustrate the different methods observed in textbooks, Table 1: In Labour Economics Textbooks presents a non-exhaustive list of methods used in the correlated labour economics textbooks; Table 2 presents a non-exhaustive list of methods used in microeconomics textbooks. An element participating

\footnotetext{
${ }^{1}$ See Weber (2002) for a discussion on whether Slutsky or Pareto introduced the separation of these effects. The method developed by Slutsky is still sometimes presented in microeconomics textbooks. See Leung and Sproule (2003) for more details

2 Hicks (1939) is also sometimes explained in studies on labour supply such as Renaud and Siegers (1984)

${ }^{3}$ Leung and Sproule (2003) and Leung, McGregor and Chesney (2014) discuss microeconomics textbooks' presentation of substitution and income effects and the gaps in their presentation.
} 


\section{Table 1: In Labour Economics Textbooks}

\begin{tabular}{|l|l|}
\hline Method & Textbooks \\
\hline Cost-Difference & Benjamin, Gunderson, Lemieux and Riddell, Labor Market Economics, $7^{\text {th }}$ \\
Samuelson & edition. \\
(1953) & Cahuc, and Zylberberg, Labor Economics. \\
\hline Compensating & Blau, Ferber and Winkler, The Economics of Women, Men and Work, $7^{\text {th }}$ \\
Variation & edition. \\
Hicks (1939) & Ehrenberg and Smith, Modern labor economics, 12 $2^{\text {th }}$ edition. \\
& Borjas, Labor economics, $6^{\text {th }}$ edition. \\
\hline
\end{tabular}

\section{Table 2: In Microeconomics Textbooks}

\begin{tabular}{|l|l|}
\hline Method & Textbooks \\
\hline $\begin{array}{l}\text { Cost-Difference } \\
\text { Samuelson } \\
(1953)\end{array}$ & Mankiw, Principles of Microeconomics, $5^{\text {th }}$ edition \\
& $\begin{array}{l}\text { Mankiw and Taylor, Microeconomics } 2^{\text {nd }} \text { edition. } \\
\text { Varian, Intermediate Microeconomics: a modern approach, 8 } \\
\text { Wikipedia (http://en.wikipedia.org/wiki/Substitution effect) on July 13, } 2016 .\end{array}$ \\
\hline $\begin{array}{l}\text { Compensating } \\
\text { Variation } \\
\text { Hicks (1939) }\end{array}$ & \\
\hline
\end{tabular}

According to microeconomics textbooks, separation of substitution and income effects is standardized as virtually all of the modern microeconomics textbooks are presenting the Cost-Difference method. However, in labour economics textbooks, both the Compensating Variation and the Cost-Difference methods are presented. It is important to mention that labour economics textbooks neither label properly the method used, nor mention the existence of an alternative method. In both microeconomics and labour economics textbooks, the Cost-Difference and the Compensating Variation methods are commonly labeled "Hicks Decomposition" regardless of whether it refers to one or the other method. This participates greatly to the confusion for students and instructors.

In their analysis of the presentation of substitution and income effects in microeconomics textbooks, Leung and Sproule (2003) have discussed whether the level of instruction (i.e. principle, intermediate or advanced) influenced the method presented in a textbook. For labour economics textbooks, there is no evidence that the targeted level of instruction is a criterion for presenting the Compensating Variation or the Cost-Difference method. Textbooks targeting the same level of instruction present one or the other.

To illustrate the discrepancy, this paper details the following; Section 1 provides a graphic illustration of a wage increase. This graph will be the framework used to describe the Compensating Variation and the Cost-Difference methods in Section 2. Section 3 advocates the standardization of the method for differentiating substitution and income effects in labour economics textbooks. 


\section{A Wage Increase}

In labour economics textbooks, substitution and income effects are presented in the context of a change in wage when an individual splits his time between market and non-market activities. Market activities are the time the individual is using to collect earnings in the labour market; these earnings will subsequently be used to purchase goods and services. Non-market activities are alternative uses of time such as leisure, consumption, housework, etc.

Figure 1: represents an individual currently working for an hourly wage (W). ${ }^{4}$ The tangency between the budget constraint and the highest attainable indifference curve determines both the consumption level (earnings) and the time devoted to non-market activities.

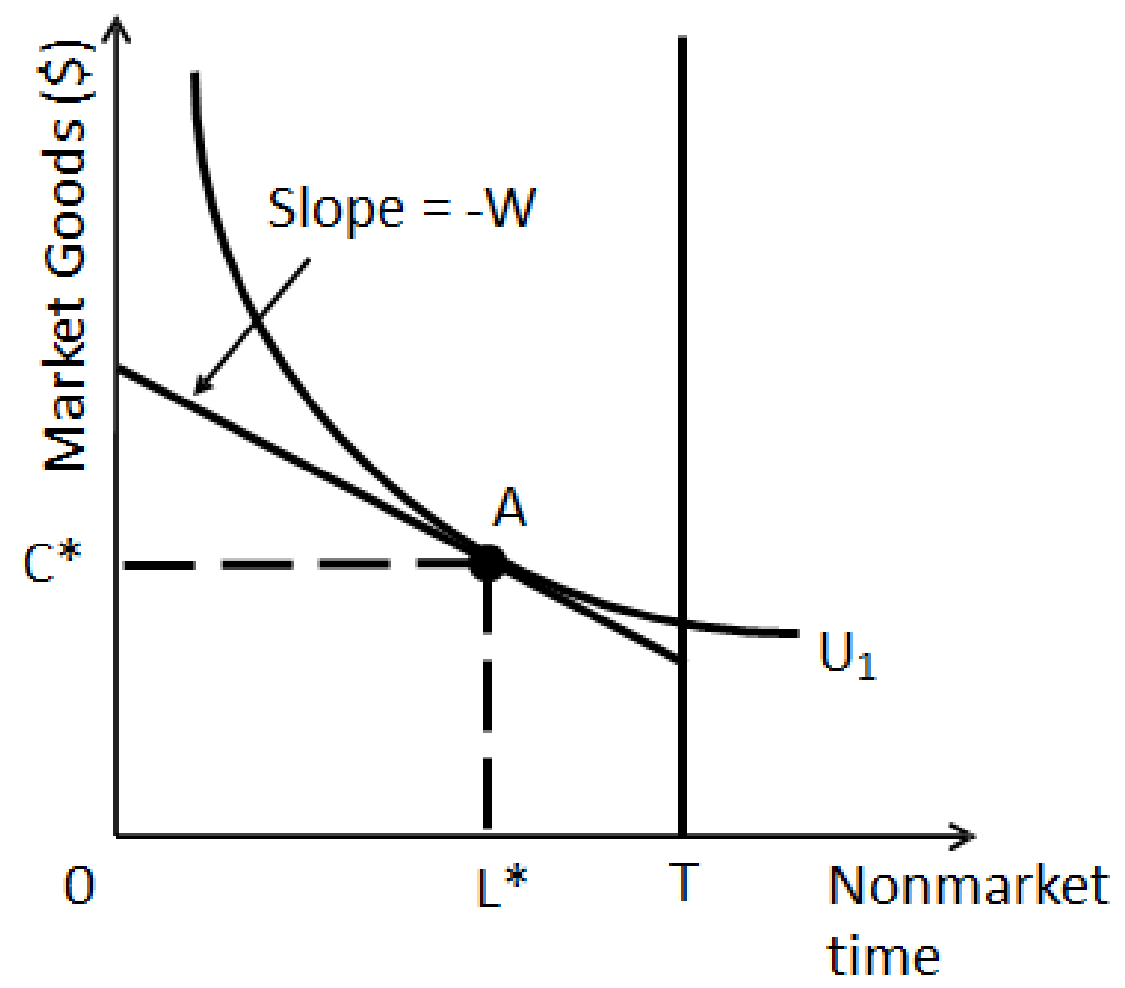

Figure 1: Initial Situation

Economic theory predicts that an individual's labour market participation changes following a wage change. However, the direction of the change cannot directly be predicted. The individual may be willing to participate more or less hours in the labour market, depending on the relative magnitude of substitution and income effects. Figure 2 considers an

\footnotetext{
${ }^{4} \mathrm{~T}$ represent the maximum available time. For example, $\mathrm{T}$ can represent twenty four hours in a day.
} 
increase in hourly wage that the individual obtains in the labour market and shows a possible situation resulting from an increase of the hourly wage to $\mathrm{W}+$.

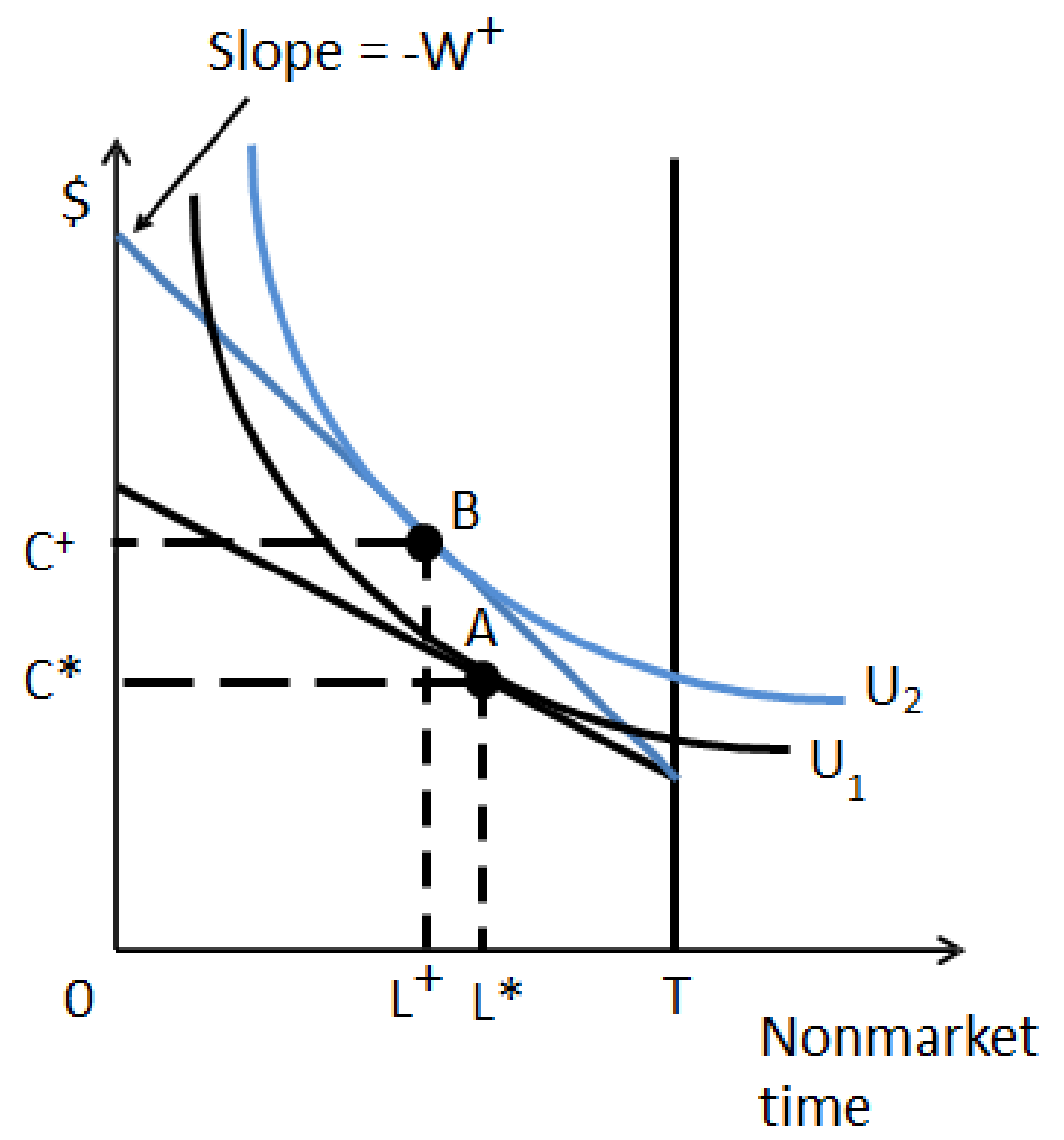

Figure 2: Wage Increase

\section{The Compensating Variation and the Cost-Difference Methods}

This section describes the two methods presented to separate substitution and income effects in various textbooks, based on the wage increase presented in Figure 2. Both methods follow a similar logic to distinguish substitution and income effects. An intermediate point is determined by taking the parallel of one of the budget constraints relative to the positioning of one the highest attainable indifference curves. Methods differ on the use of the parallel of the initial budget constraint versus the parallel of the new budget constraint. The following subsections present both methods used in labour economics textbooks. 


\section{a. The Cost-Difference Method}

The Cost-Difference method is the standard approach to distinguish between substitution and income effects in microeconomics and is presented in various major labour economics textbooks. It can be described as follows:

1. Draw the parallel of the new budget constraint that is tangent to the initial indifference curve.

2. The point of tangency is noted $\mathrm{C}$.

3. Read the abscissa of C: Lc

The Substitution Effect (SE) is $L_{A}-L_{C}$

The Income Effect (IE) is $L_{B}-L_{C}$

The Net Effect (NE) is $L_{A}-L_{B}$

Figure 3 illustrates the Cost-Difference method.

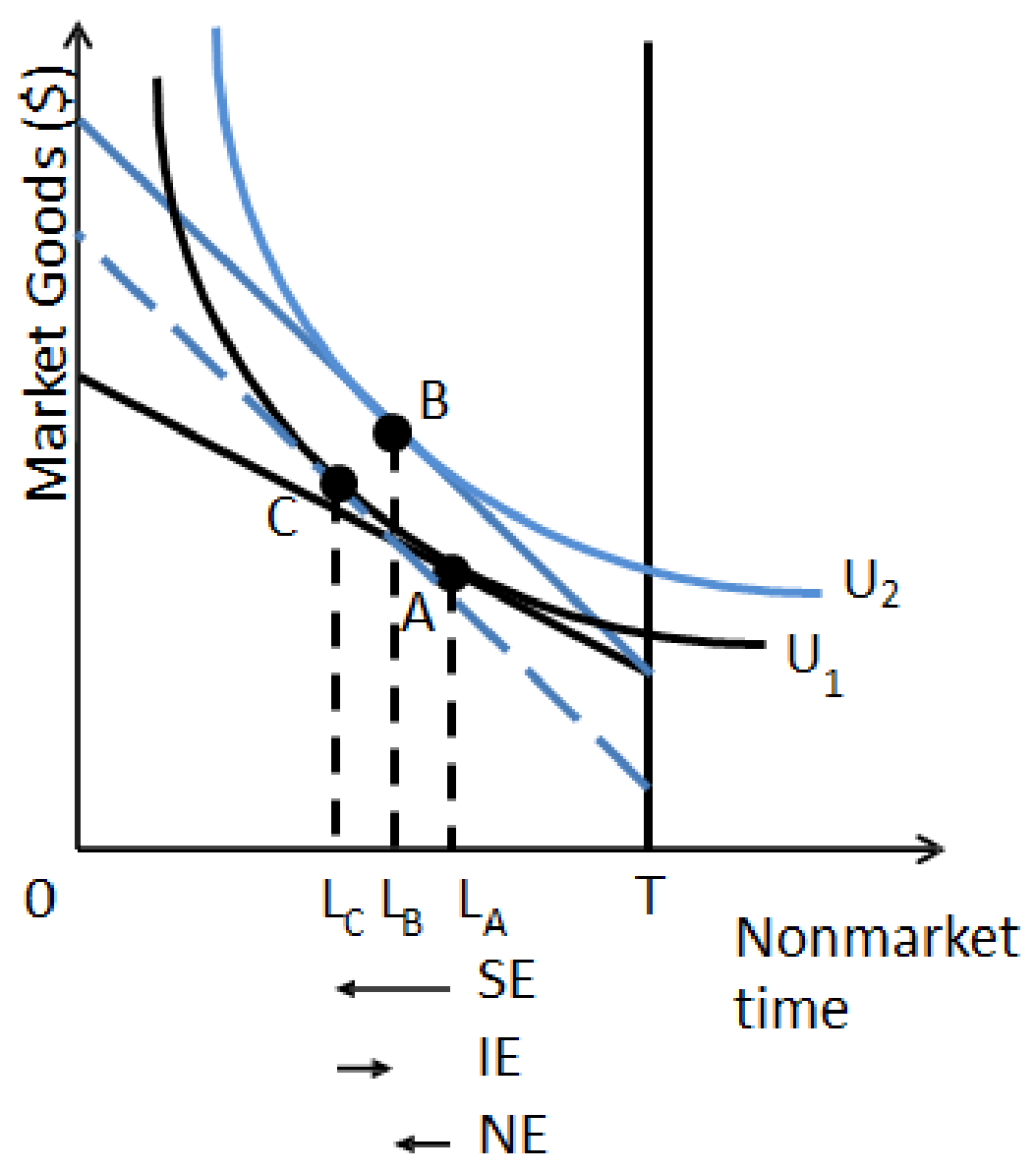

Figure 3: The Cost-Difference Method 


\section{b. The Compensating Variation Method}

The Compensating Variation method is the first refinement of the separation method developed by Slutsky. This approach does not appear in microeconomics textbooks, but is presented in various major labour economics textbooks. It can be described as follows:

1. Draw the parallel of the initial budget constraint that is tangent to the new indifference curve.

2. The point of tangency is noted $\mathrm{C}$.

3. Read the abscissa of C: Lc

The Income Effect (IE) is $L_{A}-L_{C}$

The Substitution Effect (SE) is $L_{C}-L_{B}$

The Net Effect (NE) is $L_{B}-L c$

Figure 4 illustrates the Compensating Variation method.

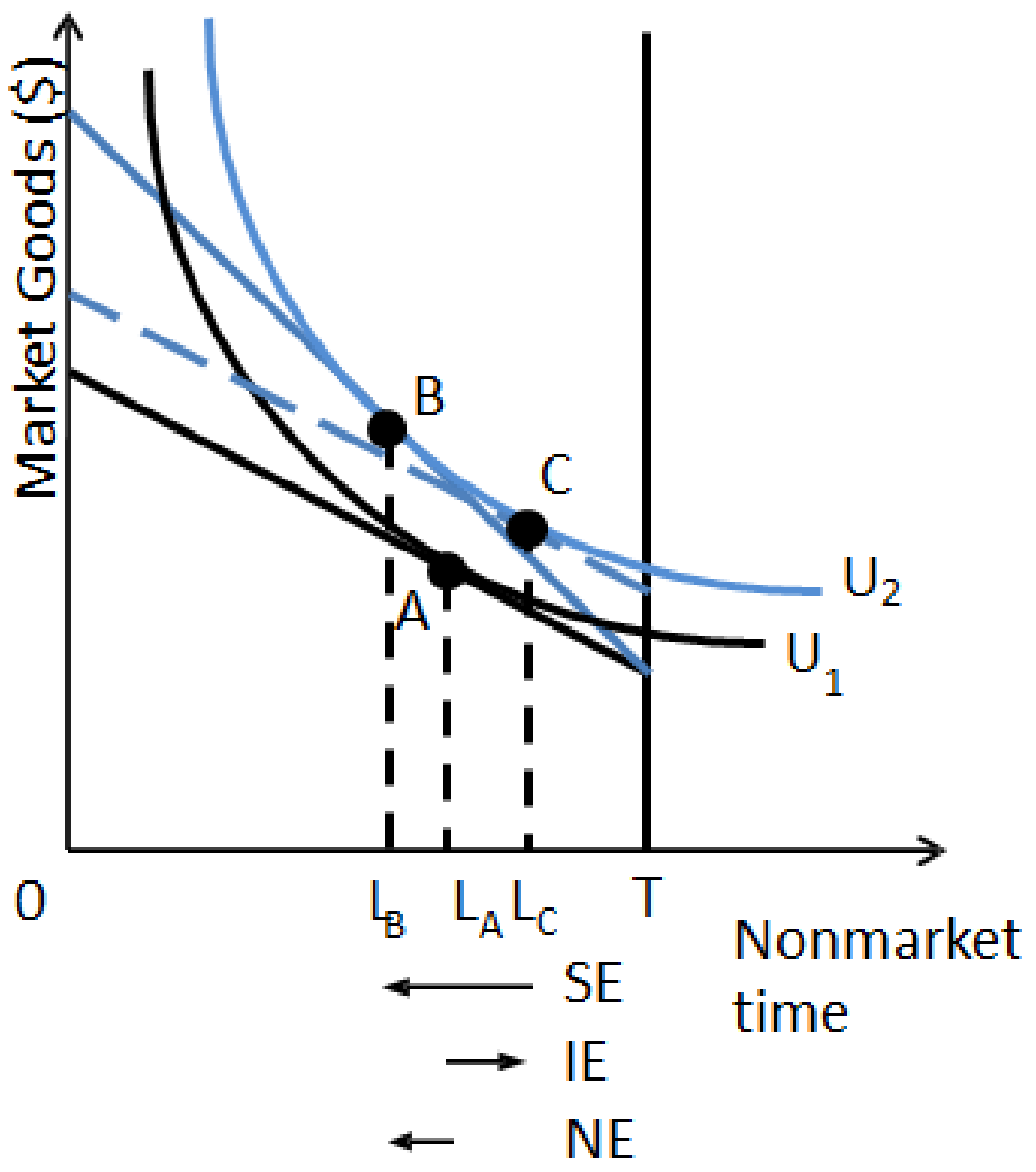

Figure 4: The Compensating Variation Method 


\section{Conclusion}

As the preceding section demonstrates, the Compensating Variation and the CostDifference methods identify substitution and income effects of different magnitudes. Many labour economics instructors are unaware of the dual methods used to determine substitution and income effects. Labour economics textbooks presenting one method appear to be unaware of the second as none of the textbooks refer to the existence of an alternative method. Methods are not labeled properly in the textbooks which reinforces the confusion. The level of instruction does not appear to be a determinant for the choice of one or the other method.

Most of the negative consequences resulting from this confusion appear during instruction. It is not rare that students, especially good ones, will access multiple resources to understand a concept or refer to learning acquired in previous courses. A student conscientiously studying could end up with his/her instructor grading an answer as incorrect when the answer was accurate according to another legitimate reference.

Therefore, standardizing methods or labeling the method used in labour economics textbooks would be logical. The Cost-Difference method appears to be the most appropriate selection as it is already the standard in microeconomics. Using this method would allow consistency not only in the study of labour economics, but also across economics curriculum.

\section{References}

Benjamin, D., Gunderson, M., Lemieux, T., \& Riddell, C. (2012). Labor market economics, $7^{\text {th }}$ edition. Toronto: McGraw-Hill Ryerson.

Blau, F. Ferber, M. and Winkler A. (2013). The Economics of Women, Men and Work, $7^{\text {th }}$ edition. Pearson.

Borjas, G. J. (2012). Labor economics, $6^{\text {th }}$ edition, Boston: McGraw-Hill.

Cahuc, P. and Zylberberg, A. (2004), Labor Economics, Cambridge, MA: the MIT Press.

Ehrenberg, R. and Smith, R. (2015). Modern Labor Economics: Theory And Public Policy, $12^{\text {th }}$ edition. Pearson.

Hicks, J.R. (1939) Value and Capital, London,

Hicks, J.R. (1956). A Revision of Demand Theory, Oxford University Press.

Leung, A., McGregor, M. and Chesney, J. (2014). Income and Substitution Effects: Graphical Analysis for Intermediate Microeconomics. Journal for Economic Educators, 14(1), 97-107.

Leung, A. and Sproule, R. (2003). The Slutsky and Hicks Decompositions in Consumption: A Seamless Perspective on the Analytics, Numerics, and Graphics. Numerics and Graphics.

Mankiw, G. (2009). Principles of Microeconomics, $5^{\text {th }}$ edition, Southwestern. 
Mankiw, G. and Taylor, M. (2011). Microeconomics, $2^{\text {nd }}$ edition. Cengage Learning.

Renaud, P. S. A. and Siegers, J. J. (1984). Income and substitution effects in family labour supply. De Economist, 132(3), 350-366.

Samuelson, P. A. (1953). Consumption theorems in terms of overcompensation rather than indifference comparisons. Economica, 20, 1-9.

Slutsky, E.E. (1915). "Sulla teoria del bilancio del consumatore" ("On the theory of the budget of the consumer") Giornale degli Economisti 51, 1-26 reprinted in A.E.A. Readings in Price Theory by G.J. Stigler and K.E. Boulding, Eds., (1952) Richard D. Irwin, Inc.: Chicago.

Varian, H. R. (2010). Intermediate Microeconomics: A Modern Approach, $8^{\text {th }}$ edition. New York, NY: WW Norton \& Company.

Weber, C. (2002). Did Pareto discover income and substitution effects? On an interpretation suggested by Hutchison. Economics Bulletin, 2(2), 1-6. 